\title{
Visitantes florais em Caatinga arbustivo-arbórea: diversidade, abundância e variação sazonal
}

\author{
Rozileudo da Silva Guedes ${ }^{1 *}$, Fernando César Vieira Zanella²
}

\begin{abstract}
RESUMO: Os antófilos desempenham papel essencial na conservação da biodiversidade. Com isso, objetivou-se caracterizar a diversidade, a abundância e a variação sazonal de visitantes florais em uma fitofisionomia de Caatinga no semiárido paraibano. A guilda de visitantes florais foi estudada por meio de amostragem sistemática dos indivíduos, em flores ou em voo, com redes entomológicas, durante um dia de cada mês, das 5 h30 às 16h30, de setembro de 2008 a agosto de 2009. Um total de 1.393 indivíduos representando 143 espécies foi registrado. Hymenoptera foi a ordem com maior riqueza em espécies (60), seguida por Lepidoptera (47) e Diptera (31). Lepidoptera foi a mais abundante (709 indivíduos), seguida por Hymenoptera (616) e Diptera (60). Foi registrado um padrão sazonal na abundância ao longo do ano para os três principais grupos de visitantes florais amostrados, com maior abundância e riqueza de espécies no período chuvoso, mas foram registradas espécies ativas durante o período seco. No intervalo entre $7 \mathrm{~h} 30$ e $8 \mathrm{~h} 30$ foi amostrada a maior riqueza e o maior número de indivíduos em atividade, sendo registradas espécies coletadas exclusivamente nos dois primeiros horários pesquisados, o que indica a sua inclusão em futuros levantamentos na Caatinga.
\end{abstract}

Palavras-chave: Antófilos, Semiárido, sazonalidade.

\section{Floral visitors in shrub-tree Caatinga: diversity, abundance and seasonal variation}

\begin{abstract}
Anthropophiles play a key role in biodiversity conservation. Thus, this study aimed to characterize the diversity, abundance and seasonal variation of floral visitors in a phytophysiognomy in Caatinga region in the Paraíba Semiarid. The guild of flower visitors was studied by means of systematic sampling of individuals in flowers or flight with entomological nets, during one day of each month, from 5:30 a.m. to 4:30 p.m., from September 2008 to August 2009. A total of 1,393 individuals representing 143 species were recorded. Hymenoptera was the order with highest species richness (60), followed by Lepidoptera (47) and Diptera (31). The order Lepidoptera was the most abundant (709 individuals), followed by Hymenoptera (616) and Diptera (60). It was recorded a seasonal pattern in abundance throughout the year for the three main groups of floral visitors sampled, with higher abundance and species richness in the rainy season, but the active species were recorded during the dry season. In the interval between 7:30 a.m. and 8:30 a.m. was sampled to greater wealth and greater number of individuals in activity being recorded species collected only in the first two hours surveyed, indicating its inclusion in future surveys in the Caatinga.

Keywords: Anthophilous, semiarid, seasonality.
\end{abstract}

\section{INTRODUÇÃO}

A Caatinga compreende uma região semiárida, com aproximadamente 912 mil $\mathrm{km}^{2}$, localizada no Nordeste brasileiro e se destaca por ser o único ecossistema exclusivo do país, composto por um mosaico de florestas secas e vegetação arbustiva (savana-estépica), com enclaves de florestas úmidas montanas e de cerrado (SILVA et al., 2017).

As modificações antrópicas na paisagem e a urbanização têm conduzido os hábitats naturais à fragmentação, destruição, e ao isolamento, com consequências negativas para a biodiversidade (FAHRIG, 2003). Dessa forma, faz-se necessário conhecer a biodiversidade presente nas comunidades locais, incluindo a dos antófilos presentes nas áreas remanescentes.
Os visitantes florais, também conhecidos por antófilos, podem ser invertebrados, como abelhas, vespas, moscas, besouros, borboletas e mariposas; ou vertebrados, principalmente beija-flores e morcegos (PROCTOR et al., 1996). Esses animais desempenham importante papel na manutenção da flora e fauna que delas dependem (IMPERATRIZFONSECA et al., 2012). Em termos de abundância os insetos são os mais importantes visitantes florais.

Em uma comunidade biológica, os antófilos desempenham um papel ecológico essencial para a conservação da biodiversidade, uma vez que os polinizadores atuam no sucesso reprodutivo e fluxo gênico de muitos grupos importantes de plantas agrícolas e florestais, sendo essas importantes fontes

Recebido em 10/05/2020; Aceito para publicação em 30/07/2020

1 Universidade Federal de Campina Grande

2 Universidade Federal da Integração Latino-Americana

*email: rozileudo@gmail.com 
de recursos alimentares para esses polinizadores (LAROCA, 1995; MORETI et al., 2006), oferecendo diferentes recursos como, pólen, néctar, tecidos florais, óleo, dentre outros (CAMARGO et al., 2011). De acordo com estimativas recentes a maioria das angiospermas conhecidas é polinizada por animais, variando de $78 \%$ em comunidades de regiões temperadas a $94 \%$ em comunidades de regiões tropicais (OLLERTON et al., 2011).

A fauna de antófilos e suas relações com as plantas em ecossistema de Caatinga são muito intrigantes, por se tratar de ambiente com condições climáticas extremas, caracterizado pela escassez de recursos florais durante a maior parte do ano (AGUIAR et al., 1995). No entanto, são escassas as informações na literatura sobre a fauna de visitantes florais nesse bioma. $\mathrm{O}$ maior número de pesquisas encontro é sobre as abelhas entre os grupos que constituem a guilda de antófilos na Caatinga (p.ex. AGUIAR; MARTINS, 1997; VIANA, 1999; ZANELLA; MARTINS, 2003; AGUIAR; ZANELLA, 2005; BATALHA FILHO et al., 2007; MILET-PINHEIRO; SCHLINDWEIN, 2008; PIGOZZO; VIANA, 2010, SILVA et al., 2012; MOURA et al., 2018; SANTOS et al., 2020).

Levantamentos com enfoque na guilda de visitantes florais são escassos, podendo citar apenas os trabalhos de Aoki e Sigrist (2006) na região Centro-oeste, e Lopes et al. (2007) e Pinheiro et al. (2008), no Sul do nosso país. Essa forma de amostragem se justifica, uma vez que, todos os visitantes florais exploram recursos similares no ecossistema e potencialmente competem por eles, interferindo uns nos outros. Além disso, características dos ambientes podem determinar diferenças na importância dos diferentes grupos de visitantes florais, e mesmo de polinizadores, e somente amostragens sistemáticas abrangendo todos os visitantes conjuntamente permitem reconhecer essas possíveis diferenças. De acordo com Aguiar e Zanella (2005) a padronização dos estudos permite ainda a comparação entre ecossistemas, e fornecem subsídios para a investigação da existência de padrões na estruturação das comunidades de antófilos na região Neotropical. Para a região da Caatinga tem-se na literatura apenas uma pesquisa e essa envolveu apenas a fauna de borboletas como visitante floral (ANSELMO et al., 2014).

Diante do exposto, este estudo teve como objetivo caracterizar a diversidade, a abundância e variação sazonal de visitantes florais em uma fitofisionomia de Caatinga, com vegetação xerófila, no semiárido paraibano.

\section{MATERIAL E MÉTODOS \\ Caracterização da área de estudo}

$\mathrm{O}$ estudo foi realizado em fragmento de vegetação que constitui a Reserva Legal da Fazenda Tamanduá $\left(7^{\circ} 01^{\prime} \mathrm{S}, 37^{\circ} 24^{\prime} \mathrm{W}\right)$, propriedade da Mocó Agropecuária Ltda., localizada no município de Santa Terezinha, Paraíba. Na propriedade existe uma Reserva Particular do Patrimônio Natural (RPPN) que é preservada há cerca de 40 anos, além da área de reserva legal. Há a presença de apiários, de plantação de manga irrigada o ano todo, de pastagem irrigada para atender ao gado bovino, e alguns açudes.

As coletas ocorreram em um remanescente de Caatinga com área de aproximadamente 20 ha em preservação. A comunidade vegetal estudada apresenta fisionomia arbustivo-arbórea aberta, onde se sobressaem indivíduos arbóreos, com a presença de estrato herbáceo relativamente denso durante o período chuvoso, que seca totalmente no período de estiagem.

O município de Santa Terezinha está inserido na Mesorregião do Sertão Paraibano, na Microrregião de Patos. A região apresenta o tipo climático tropical semiárido (Bsh), segundo a classificação de Köppen, caracterizando um clima quente e seco (ÁLVARES et al., 2013).

Os dados referentes à precipitação do período de estudos foram obtidos a partir de uma miniestação pluviométrica instalada na própria propriedade de estudo e os dados referentes à temperatura e umidade relativa foram obtidos para o município de Patos na estação da Universidade Federal de Campina Grande que fica a aproximadamente $20 \mathrm{~km}$ da área de estudo. $\mathrm{Na}$ análise da sazonalidade dos visitantes florais considerou-se período chuvoso os meses de janeiro a junho de 2009, e os demais meses durante o período estudado como parte do período seco. Durante o período de estudo, as chuvas foram abundantes, sendo um ano atípico. A precipitação média anual na área de estudo foi de $1.280,9 \mathrm{~mm}$. O mês de abril foi o mais chuvoso, com um total de $448 \mathrm{~mm}$ e os meses mais secos foram setembro, outubro e novembro nos quais não houve precipitação. A temperatura média anual foi de $27,2^{\circ} \mathrm{C}$, com temperatura máxima de $39,0^{\circ} \mathrm{C}$ no mês de dezembro/2008 e mínima de $18,4^{\circ} \mathrm{C}$ em julho/2009.

\section{Metodologia de amostragem e Análise dos dados}

A amostragem dos visitantes florais foi baseada no método de Sagakami et al. (1967) com algumas modificações. As coletas foram realizadas mensalmente de setembro de 2008 a agosto de 2009, com intervalos de aproximadamente 30 dias, cada uma realizada em um único dia (com condições atmosféricas favoráveis) e com seis horas de duração, com exceção do mês de abril que devido às 
chuvas, as coletas não puderam ser finalizadas, sendo concluídas após dois dias. A área de estudo foi dividida em 6 transectos, cada um possuindo 200 metros de comprimento e $4 \mathrm{~m}$ de largura, totalizando $4.800 \mathrm{~m}^{2}$. O transecto foi percorrido das $5 \mathrm{~h} 30 \mathrm{~min}$ às $16 \mathrm{~h} 30 \mathrm{~min}$ horas por um coletor, em intervalos de uma hora (5h30-6h30; 7h30-8h30; 9h30-10h30; 11h30-12h30; 13h30-14h30; e 15h30-16h30). As modificações foram feitas no esquema original de amostragem com os seguintes propósitos: 1) a coleta em horários distribuídos desde o amanhecer até o anoitecer para se avaliar a variação diária na atividade dos visitantes florais e 2) a coleta ou registro de todos os visitantes florais, para se avaliar a abundância relativa do conjunto dos componentes da guilda de grupos que utilizam recursos florais.

A cada dia de coleta, os transectos foram percorridos alternadamente. A cada hora um transecto foi percorrido explorando as plantas floridas, e regsitrando e/ou capturando os visitantes florais. Nos horários de intervalos foi realizada a coleta de material botânico para confecção das exsicatas e, também, a organização dos insetos capturados.

Os visitantes foram capturados (individualmente ou em grupo) durante a visita às flores ou em voo com o auxílio de redes entomológicas, sacrificados em frascos mortíferos contendo acetato de etila e acondicionados ao final da hora de coleta em frascos plásticos etiquetados com o horário, a data e o nome da planta visitada. Apis mellifera L. não foi capturada devido ao fácil reconhecimento desta espécie no campo, adotando-se apenas o registro visual (por estimativa) para avaliação de sua abundância, conforme Zanella (2003). Para isso, a área com flores foi dividida visualmente em setores de cerca de $1 \mathrm{~m}^{2}$. Após uma rápida contagem dos indivíduos em cada setor, era anotado o somatório de todos os setores.

No caso de lepidópteros, como a coleta demanda mais tempo, foram coletados exemplares representativos das espécies e realizou-se o registro da frequência em flores ou em voo nos horários de coleta. Para os beija-flores, adotou-se apenas o registro visual durante a visita às flores.

Todos os visitantes capturados foram montados em alfinetes entomológicos, secos em estufa, etiquetados, registrados no banco de dados e depositados na coleção do Laboratório de Ecologia e Biogeografia de Insetos da Caatinga (LEBIC) da Universidade Federal de Campina Grande (UFCG), Campus de Patos, Paraíba.

Foi coletado e herborizado o material botânico fértil de todas as espécies vegetais floridas a cada mês, segundo métodos usuais em botânica. O material coletado foi herborizado e incorporado ao herbário Lauro Pires Xavier do Departamento de Sistemática e Ecologia da Universidade Federal da Paraíba (UFPB). A identificação das espécies foi realizada por comparação com material herborizado e por consulta a especialistas. A nomenclatura adotada para as famílias foi a do sistema de classificação de angiospermas, o Angiosperm Philogeny Group IV (APG IV, 2016).

Os insetos coletados foram morfotipados e classificados em termos de Ordem. As espécies de borboletas citadas com nome de espécie foram reconhecidas por comparação com exemplares da região identificados pelo Dr. Olaf Mielke (UFPR), a partir de imagens digitalizadas. As espécies de abelhas foram identificadas por comparação com material depositado na coleção da UFCG.

A constância dos visitantes florais, que demonstra a relação entre a proporção dos dias em que a espécie i foi coletada e o número total de dias amostrados, foi categorizada conforme Silveira Neto et al. (1976), sendo constante, as espécies presentes em mais de $50 \%$ das coletas; acessória, entre 25 e $50 \%$; e acidental, em menos de $25 \%$ das coletas.

A dominância das espécies foi definida de acordo com as seguintes categorias estabelecidas a partir da abundância relativa de cada espécie, sendo eudominante > 10\%, dominante > $>5-10 \%$, subdominante $>2-5 \%$, recessiva $=1-2 \%$ e rara $<$ $1 \% . \mathrm{D} \%=(\mathrm{i} / \mathrm{t}) .100$, onde i é o total de indivíduos de uma espécie e to total de indivíduos coletados.

Para a estimativa da riqueza de espécies foi utilizado o estimador Chao1, por meio da seguinte fórmula: (Sest $=$ Sobs $+\left(a^{2} / 2 b\right)$, onde $S=$ número de espécies, estimado e observado, $\mathrm{a}=$ número de espécies com um indivíduo e $\mathrm{b}=$ número de espécies com dois indivíduos, conforme Colwell (2005).

A diversidade de visitantes florais foi estimada utilizando-se os índices de Shannon-Weaver ( $\left.\mathrm{H}^{\prime}\right)$, de Simpson_1-D (C) e da Equitabilidade de Pielou (J) (MAGURRAN, 2011). A análise dos dados foi realizada utilizando o Software Past (HAMMER et al., 2001).

\section{RESULTADOS E DISCUSSÃO}

Riqueza e abundância. A composição da fauna de visitantes florais amostrada na área de estudo foi representada por cinco táxons de animais, sendo um de ave e quatro de insetos pertencentes às seguintes ordens: Lepidoptera, Hymenoptera, Diptera e Coleoptera. Durante o período de estudo foi registrado um total de 1.393 indivíduos, correspondendo a 142 espécies de insetos e uma espécie de pássaro (Tabela 1).

Tabela 1. Número de espécies e indivíduos de visitantes florais por táxon amostrados, no período de setembro de 2008 a agosto de 2009, em um remanescente de caatinga, Santa Terezinha, Paraíba. 


\begin{tabular}{ccccc}
\hline Táxon & $\mathbf{N}^{\mathbf{0}}$ de Espécies & Espécies (\%) & $\mathbf{N}^{\mathbf{0}}$ de Indivíduos & Indivíduos (\%) \\
\hline Hymenoptera & 60 & 41,9 & 616 & 44,2 \\
Lepidoptera & 47 & 32,9 & 709 & 50,9 \\
Diptera & 31 & 21,7 & 60 & 4,3 \\
Coleoptera & 4 & 2,8 & 6 & 0,4 \\
Aves & 1 & 0,7 & 2 & 0,1 \\
\hline Total & $\mathbf{1 4 3}$ & $\mathbf{1 0 0 , 0}$ & $\mathbf{1 . 3 9 3}$ & $\mathbf{1 0 0 , 0}$ \\
\hline
\end{tabular}

Hymenoptera foi a mais representativa em riqueza de espécies com 41,9\%, seguida por Lepidoptera e Diptera com 32,9 e 21,7\%, respectivamente. Essa sequência de representatividade em riqueza de espécies dos táxons de visitantes florais, encontrados na área de estudo foi também observada no sul do Brasil por Lopes et al. (2007). No entanto, foi encontrada sequência diferente em outros estudos por Pascarella et al. (2001), na Flórida, com Diptera, Lepidoptera e Hymenoptera (mas esses autores não amostraram as abelhas, caso estas fossem incluídas possivelmente a sequência seria Hymenoptera, Diptera e Lepidoptera), e por Aoki e Sigrist (2006), para o Cerrado brasileiro, com Hymenoptera, Diptera e Coleoptera como as ordens mais ricas em espécies.

A ordem Lepidoptera foi a segunda em riqueza de espécies (47), sendo esse número mais alto comparado ao obtido em outros levantamentos que envolveram várias ordens de visitantes florais (37 spp. - LOPES et al., 2007, em Triunfo, no Rio Grande do Sul; 42 spp. - PASCARELLA et al., 2001; na Flórida, nos Estados Unidos; e 43 spp. AOKI; SIGRIST, 2006, no Complexo AporéSucuriú, no Mato Grosso do Sul).

Lepidoptera e Hymenoptera foram as mais abundantes e as demais ordens representaram apenas $4,8 \%$ do total de indivíduos amostrados (Tabela 1). Lopes et al. (2007) registraram sequência diferente, em relação a este estudo, com Hymenoptera,
Lepidoptera e Diptera como as mais abundantes em número de indivíduos, respectivamente.

A análise da abundância da fauna de visitantes florais amostrada evidenciou um predomínio de espécies raras, ou seja, um número reduzido de espécies representado por um grande número de indivíduos e um elevado número de espécies com apenas um indivíduo. A maioria das espécies $(\mathrm{n}=71)$ o equivalente a $49,7 \%$ do total amostrado, contribuiu com apenas um indivíduo, padrão semelhante foi registrado por Lopes et al. (2007) no Rio Grande do Sul. Segundo Andena et al. (2005), esse padrão é esperado para amostragens realizadas em ecossistemas neotropicais.

Esses padrões de abundância das espécies distintos resultam em diferenças na estimativa da riqueza presente na área para os diferentes grupos. Se utilizarmos o estimador Chao1, que utiliza a relação entre o número de espécies representadas por somente um e dois indivíduos na amostra, temos para o conjunto dos visitantes florais uma riqueza estimada de 276 espécies. De modo que por essa estimativa, $48 \%$ das espécies presentes na área não foram coletadas. Considerando o número de espécies estimadas para os principais táxons de visitantes florais, observa-se na Tabela 2 que dípteros e himenópteros têm o maior número de espécies estimadas e que a ordem que obtive o maior número de espécies coletadas foi a Lepidoptera em comparação a riqueza estimada.

Tabela 2. Número de espécies estimadas pelo estimador Chao1, número de espécies singletons e doubletons, número de espécies estimadas e coletadas para os principais táxons de visitantes florais em um remanescente de caatinga, Santa Terezinha, Paraíba.

\begin{tabular}{lcccc}
\hline \multirow{2}{*}{ Ordens } & \multicolumn{4}{c}{ Espécies } \\
\cline { 2 - 5 } & Singletons & Doubletons & Estimadas & Observadas \\
\hline Hymenoptera & 29 & 10 & 102,05 & 60 \\
Lepidoptera & 18 & 6 & 74,00 & 47 \\
Diptera & 21 & 2 & 141,25 & 31 \\
\hline
\end{tabular}

Dominância. Em relação à dominância das espécies amostradas, observou-se que somente duas espécies (1\%) foram categorizadas como eudominantes: Apis mellifera L. (1758) (Hymenoptera) e Eurema elathea Cramer (1777) (Lepidoptera) com 31 e 27\%, respectivamente. Não houve espécies que se caracterizassem como dominante. Ocorreram poucas espécies categorizadas como subdominante $(3 \%)$ ou recessiva (3\%) e o maior valor encontrado foi para as espécies raras, com $93 \%$ do total amostrado.
Lopes et al. (2007) em estudos com antófilos no Rio Grande do Sul, não registraram qualquer espécie categorizada como eudominante ou dominante e semelhante a este estudo também amostraram um grande número de espécies raras.

Índices de diversidade. A análise faunística dos grupos de visitantes florais amostrados neste estudo demonstrou um índice de diversidade de Shannon $\left(\mathrm{H}^{\prime}\right)$ para a área de estudo estimado em 2,804 nats.ind $^{-1}$ e 0,82 para Simpson (C) (Tabela 3). O 
índice de Shannon-Wiever expressa a uniformidade dos valores por meio de todas as espécies; já o índice de diversidade de Simpson é influenciado pela abundância das espécies dominantes.

A diversidade alfa na área estudada é menor quando comparada com o obtido por Lopes et al.
(2007), em estudo com antófilos em ambiente com reflorestamento de eucalipto e mata ciliar no Rio Grande do Sul, que citaram valor de H' em torno de 4,0 nats.ind $^{-1}$, influenciado pela maior equitabilidade observada entre as abundâncias das espécies.

Tabela 3. Número de espécies (NE), Número de indivíduos (NI), Índice de Shannon (H'), Índice de Simpson (C) e Equitabilidade (J) estimados para a comunidade de visitantes florais e para as principais ordens de visitantes florais amostrados em um remanescente de Caatinga, em Santa Terezinha, Paraíba.

\begin{tabular}{|c|c|c|c|c|c|}
\hline Visitantes florais & NE & NI & $\mathbf{H}^{\prime}$ & $\mathbf{C}$ & $\mathbf{J}$ \\
\hline Total & 143 & 1393 & 2,804 & 0,8236 & 0,565 \\
\hline Ordens & NE & NI & $\mathbf{H}^{\prime}$ & C & $\mathbf{J}$ \\
\hline Diptera & 31 & 60 & 3,158 & 0,9450 & 0,9197 \\
\hline Lepidoptera & 47 & 709 & 2,110 & 0,6976 & 0,5483 \\
\hline Hymenoptera & 60 & 616 & 1,618 & 0,4990 & 0,3951 \\
\hline
\end{tabular}

A comparação dos índices de diversidade para os principais grupos de insetos visitantes florais amostrados neste estudo e a riqueza de espécies efetivamente amostrada demonstra a forte influência dos padrões de abundância relativa. Pode-se perceber que a comparação entre os índices é mais semelhante às riquezas estimadas por grupo, do que ao número de espécies coletadas. Os índices de diversidade foram maiores para os dípteros, seguidos pelos lepidópteros e himenópteros (Tabela 3). O maior índice de diversidade alcançado pela ordem Diptera está associado à alta uniformidade entre abundâncias das espécies. Contudo, todas as espécies apresentaram dominância categorizada como raras, ou seja, apresentaram abundância relativa menor que $1 \%$. A ordem Diptera foi a terceira em número de espécies (31 spp.), porém, com baixa abundância (60 indivíduos).

A riqueza de espécies de dípteros foi superior à registrada por Lopes et al. (2007) (21 spp.) e inferior aos registrados por Pascarella et al. (2001) (55 spp.) e Aoki e Sigrist (2006) (89 spp.). A polinização por moscas é irregular e não confiável, pois em geral utilizam diferentes fontes de alimento. No entanto, os dípteros podem ser importantes polinizadores, pois geralmente algumas moscas estão presentes ao longo de todo o ano (FAEGRI; VAN DER PIJL, 1979). Na Caatinga, a abundância das espécies de dípteros antófilos aparentemente é baixa, mas é possível que espécies de plantas com síndrome de polinização por moscas (miofilia) não tenham sido incluídas na amostragem e, além disso, é necessário estudar outras unidades de paisagem para verificar se esse padrão se repete.

Pelo número de espécies amostradas para Lepidoptera esperava-se um maior índice de diversidade, mas a grande abundância de Eurema elathea na área implicou em uma equitabilidade intermediária, o que influenciou no valor de $H^{\prime}$.
Quanto aos himenópteros como a maior parte do total amostrado pertence à espécie Apis mellifera $(70,3 \%)$, isso resultou na equitabilidade mais baixa entre as três ordens mais abundantes analisadas, e consequentemente no menor índice de diversidade de Shannon (H').

Variação sazonal na riqueza e abundância de visitantes florais. Com relação à sazonalidade da comunidade, observa-se que os visitantes florais foram coletados ao longo de todo o período estudado, com exceção do mês de setembro que não foi registrado nenhum antófilo em atividade em função de não haver plantas floridas na área pesquisada.

A riqueza e a abundância de visitantes florais foram maiores no período chuvoso (Tabela 4), especialmente entre março e junho, com a maior riqueza de espécies registrada no mês de abril e a maior abundância de indivíduos em maio de 2009 (Figura 1). No período chuvoso, de janeiro a junho, foram amostrados $79,8 \%$ dos indivíduos e $88,1 \%$ das espécies, enquanto que no período seco (julho a dezembro), foram registrados $20,2 \%$ dos indivíduos e $39,9 \%$ das espécies. Aproximadamente $30 \%$ das espécies ocorreram nos dois períodos. Se restringirmos apenas ao final do período seco, de outubro a dezembro, que corresponde ao período mais crítico, foram registradas apenas $9,8 \%$ (14) das espécies de visitantes florais. No início do período chuvoso, a riqueza e a abundância são baixas por certo tempo, pois o desenvolvimento, das plantas e dos insetos, requer um certo tempo até o florescimento e a emergência de insetos adultos. E de modo correspondente, no início do período seco ainda há umidade no solo, o que mantém a vegetação verde por certo tempo, incluindo ervas com flores e permite a manutenção de uma diversidade de insetos, conforme observado por Zanella e Martins (2003) para abelhas. 
Tabela 4. Riqueza e abundância total para as principais ordens de visitantes florais, nos períodos chuvoso (jan-jun) e seco (jul-dez), em área de caatinga na Fazenda Tamanduá, Santa Terezinha, Paraíba.

\begin{tabular}{lcccc}
\hline \multirow{2}{*}{ Visitantes Florais } & \multicolumn{2}{c}{ Período Chuvoso } & \multicolumn{2}{c}{ Período Seco } \\
\cline { 2 - 5 } & $\mathrm{N}^{\mathbf{o}}$ de espécies & $\mathrm{N}^{\mathbf{o}}$ de indivíduos & $\mathrm{N}^{\mathbf{o}}$ de espécies & $\mathrm{N}^{\mathbf{0}}$ de indivíduos \\
\hline Hymenoptera & 53 & 489 & 25 & 127 \\
Lepidoptera & 39 & 560 & 28 & 149 \\
Diptera & 30 & 57 & 3 & 3 \\
Outras ordens & 4 & 6 & 1 & 2 \\
\hline Total & 126 & 1.112 & 57 & 281 \\
\hline
\end{tabular}

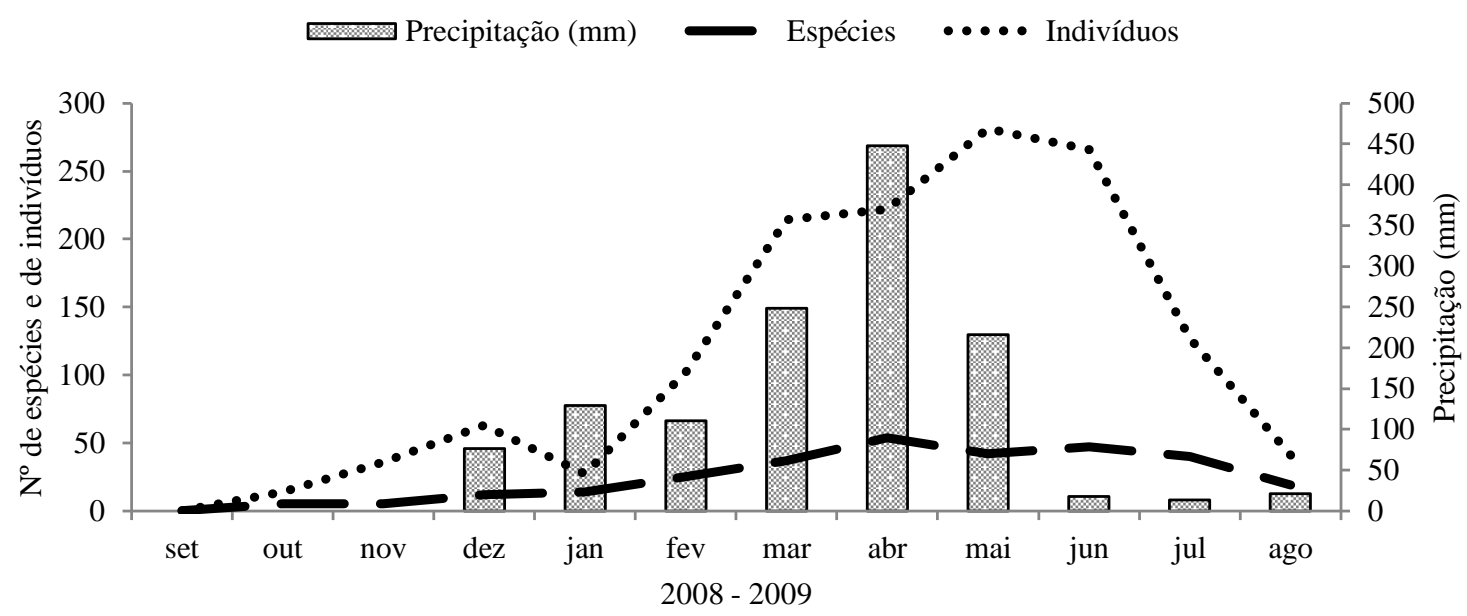

Figura 1- Distribuição mensal do número de espécies e de indivíduos visitantes florais amostrados e precipitação pluviométrica mensal, em área de Caatinga, na Fazenda Tamanduá, Santa Terezinha, PB, de setembro de 2008 a agosto de 2009.

Percebe-se uma relação direta entre a redução de visitantes florais e o início da estação seca. Há uma queda drástica no número de antófilos logo no início do período de estiagem, de junho (266) para julho (127) e deste mês para agosto (41), sendo a menor abundância registrada em setembro. É interessante destacar que o número de espécies em atividade demorou mais para decrescer, não sendo observada uma queda acentuada de junho (46) para julho (39) (Figura 1). Aparentemente, há uma redução generalizada na abundância das espécies com a chegada das condições adversas, relacionadas essencialmente à acentuada redução na disponibilidade de plantas floridas na área. $\mathrm{O}$ mês de setembro, período seco de 2008, foi o único mês durante o período de estudo que não houve recursos florais disponíveis em qualquer dos seis transectos. A área estudada, apesar de percorrida, não foi encontrado visitante floral. Os recursos que a comunidade vegetal estudada oferece aos visitantes florais neste período são todos por meio das espécies arbustivas e arbóreas, a exemplo da Amburana cearensis, Anadenanthera colubrina e Capparis flexuosa, uma vez que o estrato herbáceo seca completamente, além das áreas no entorno de açudes que são áreas de exceção próximas.

Com relação aos grupos mais abundantes de visitantes florais amostrados, observou-se que em geral houve presença de indivíduos de cada grupo durante o período pesquisado, com variação na riqueza de espécies e nas abundâncias ao longo do ano. Lepidópteros e himenópteros ocorreram durante todo o ano, excetuando-se o mês de setembro, mas é provável que houvesse espécies ativas na região, que não foram registradas no local de amostragem devido à ausência de flores. Os dípteros também ocorreram ao longo do ano, mas não foram registrados em novembro, julho e agosto, além de setembro. As maiores abundâncias de lepidópteros ocorreram um pouco após o início do período chuvoso, em março e abril, que corresponde ao início do período de maior abundância de visitantes florais. Para os himenópteros e dípteros foi observado um crescimento no número de indivíduos ao longo do período chuvoso, porém os himenópteros apresentaram um pico nos meses de maio e junho (Figura 2).

Durante o período de baixa precipitação, os visitantes florais apresentaram baixas abundâncias e na estação chuvosa as maiores abundâncias. Porém, os indivíduos de cada grupo apresentaram picos de abundância em diferentes meses: lepidópteros em março, himenópteros em maio, e dípteros em junho (Figura 2). 


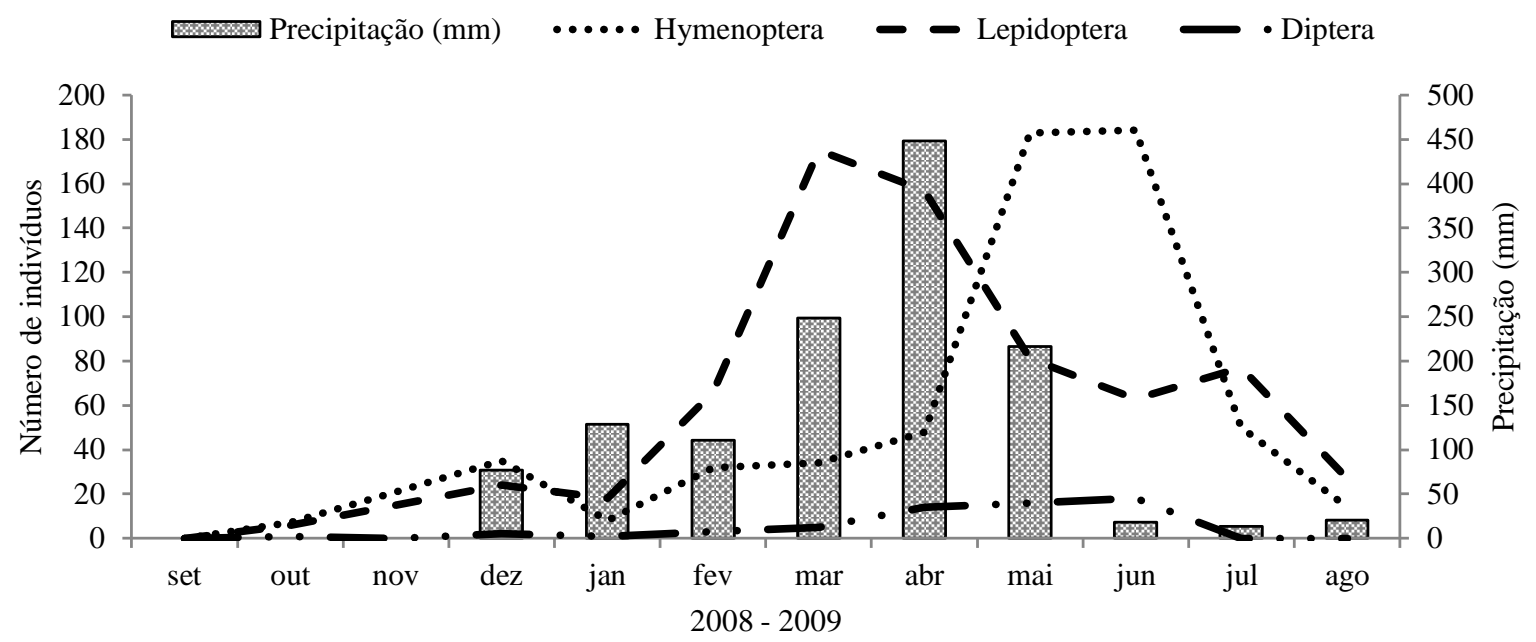

Figura 2 - Variação do número de indivíduos em atividade dos táxons mais abundantes, amostrados de setembro de 2008 a agosto de 2009, em vegetação de Caatinga na Reserva Legal da Fazenda Tamanduá, Santa Terezinha, Paraíba.

Dentre os himenópteros, há espécies sociais que podem apresentar padrões sazonais de atividade diferentes das outras espécies. Para as abelhas, existem espécies eussociais, que apresentam colônias permanentes e devem estar ativas ao longo de todo o ano. Neste estudo, foi registrada somente Apis mellifera como eussocial. Essa espécie exótica representou $70,3 \%$ do total de himenópteros registrados, com 433 indivíduos.

Há ainda espécies de vespas sociais, as quais formam colônias, mas nesse caso a fundação dos ninhos pode ser realizada por apenas um indivíduo. Apesar disso, podem-se encontrar ninhos ativos dessas espécies durante a estação seca. Em levantamentos com abelhas em áreas de Caatinga tem sido registrada uma forte sazonalidade com concentração da abundância no período chuvoso (ZANELLA; MARTINS, 2003), mas várias espécies de abelhas não-eussociais permanecem ativas durante o período seco. Já a forte variação na abundância de Apis é característica para áreas secas de Caatinga, quando essas abelhas devem abandonar seus ninhos na área se deslocando para setores onde haja disponibilidade de recursos florais (FREITAS et al., 2007).

Neste trabalho foram registradas as seguintes espécies com indivíduos adultos ativos durante os meses de outubro, novembro e dezembro, que corresponde ao período mais intenso de seca: Hymenoptera [Apis mellifera, Xylocopa grisescens Lepeletier, 1841, Polybia ignobilis (Haliday, 1836), Proctonectarina sylvetrae (Saussure, 1854), Centris sp. e Protopolybia sp.], Diptera [Palpada vinetorum (Fabricius, 1779)] e mais duas espécies não identificadas), Lepidoptera (Eurema elathea, Hemiargus hanno (Stoll, 1790) e mais duas espécies não identificadas] e uma espécie de beija-flor.

Os resultados da distribuição da abundância tanto do número de espécies quanto de indivíduos de abelhas ao longo do ano demonstram que há um grande decréscimo durante o período seco em relação ao período chuvoso na caatinga, ratificando as informações existentes para o grupo na região. No entanto, os resultados confirmam que para outros grupos de antófilos também há uma redução significativa no período seco (tanto na riqueza de espécies como na abundância) nessa região, mas por outro lado, da mesma forma que para o grupo das abelhas demonstra também que aparentemente há espécies que se mantêm ativas durante o período seco.

Constância das espécies. Do total de espécies amostradas nove $(6,3 \%)$ foram categorizadas como constantes, tendo sido amostradas em pelo menos seis meses, dentre elas cinco lepidópteros: Eurema elathea, Ascia monuste orseis (Godart, 1819), Hemiargus hanno, Chioides cf. catillus (Cramer, 1780) e Pyrgus cf. orcinoides (Giacomelli, 1928) e quatro himenópteros: Apis mellifera, Xylocopa grisescens, Polybia ignobilis e Pepsis decorata Perty, 1833. As espécies acessórias perfizeram um total de $16,8 \%$ e a grande maioria das espécies foi considerada acidental $(76,9 \%)$. Isso não implica que elas ocorram somente em poucos meses do ano, mas pode ser somente devido ao pequeno número de indivíduos amostrados.

As espécies Apis mellifera (Hymenoptera) e Eurema elathea (Lepidoptera) foram as espécies mais abundantes sendo responsáveis por $58,3 \%$ do total de visitantes florais. A distribuição mensal da abundância dessas espécies ao longo do período estudado demonstrou alta frequência na comunidade, sendo observada variação sazonal com elevada abundância no período chuvoso, mas apresentando indivíduos ativos no período seco. A constância dessas espécies na área está associada ao hábito generalista na utilização dos recursos, sendo 
capazes de substituir suas fontes alimentares de acordo com sua disponibilidade na área pesquisada.

Variação na atividade diária de visitantes florais. Os visitantes florais foram coletados em todos os horários de amostragem e os com maior frequência de registros foram entre $7 \mathrm{~h} 30$ e $8 \mathrm{~h} 30$ e entre $9 \mathrm{~h} 30$ e 10h30. A frequência de visitantes foi maior pela manhã, com 58,5\% dos registros. Aguiar e Martins (1997), estudando abelhas em área de caatinga em São João do Cariri, registraram padrão semelhante com decréscimo de indivíduos amostrados no período da tarde sendo o primeiro horário de amostragem, entre 8 e 9 horas o que apresentou maior frequência de registros. Viana (1999) também observou menor abundância no horário vespertino em Ibiraba, BA.

Esse decréscimo do número de visitantes florais em atividade no período da tarde ocorreu para os grupos de insetos mais abundantes amostrados (Figura 3). Provavelmente essa diminuição na atividade no período da tarde está associada à diminuição no fornecimento de néctar e pólen pelas flores de muitas espécies, associado ao aumento da temperatura, o que concorda com as observações de Viana (1999) em Ibiraba (BA).

A maior riqueza e abundância de visitantes florais em atividade foram registradas no segundo intervalo de hora estudado (7h30-8h30), enquanto que a menor riqueza e a abundância foram registradas entre $15 \mathrm{~h} 30$ e $16 \mathrm{~h} 30$ (Figura 3). Todos os visitantes florais apresentaram redução da abundância ao longo do dia e os lepidópteros demonstraram a maior riqueza de espécies em todos os horários estudados.

No primeiro intervalo (de 5 h30 às 6h30) coletouse $14,29 \%$ do total de insetos amostrados. Este estudo é o primeiro a incluir esta faixa de horário em um levantamento sistemático de insetos, por não ser um horário de grande atividade dos insetos antófilos. Porém, é um horário importante de atividade de forrageio de visitantes florais na Caatinga na estação seca, devido às temperaturas mais amenas. Neste período, observaram-se quatro espécies (duas de abelhas e duas de borboletas) que só foram observadas nesta faixa de horário e só apresentaram um indivíduo cada.

No segundo horário, entre $7 \mathrm{~h} 30$ e $8 \mathrm{~h} 30$, foi observada a maior abundância e riqueza de espécies de visitantes florais, tendo sido coletadas 19 espécies somente nesse intervalo. Duas outras espécies foram coletadas somente nos dois primeiros horários. Esse resultado difere do observado por Schwartz Filho e Laroca (1999) que, em levantamento de abelhas realizado no litoral do Paraná, registraram apenas uma espécie, Euplusia hatchbachii Moure, observada entre 7 e 8 horas, que não foi coletada nos horários entre 9 h30 e 14h30, e observam que a amostragem faunística nesse horário mais cedo pode ser dispensável naquela região.

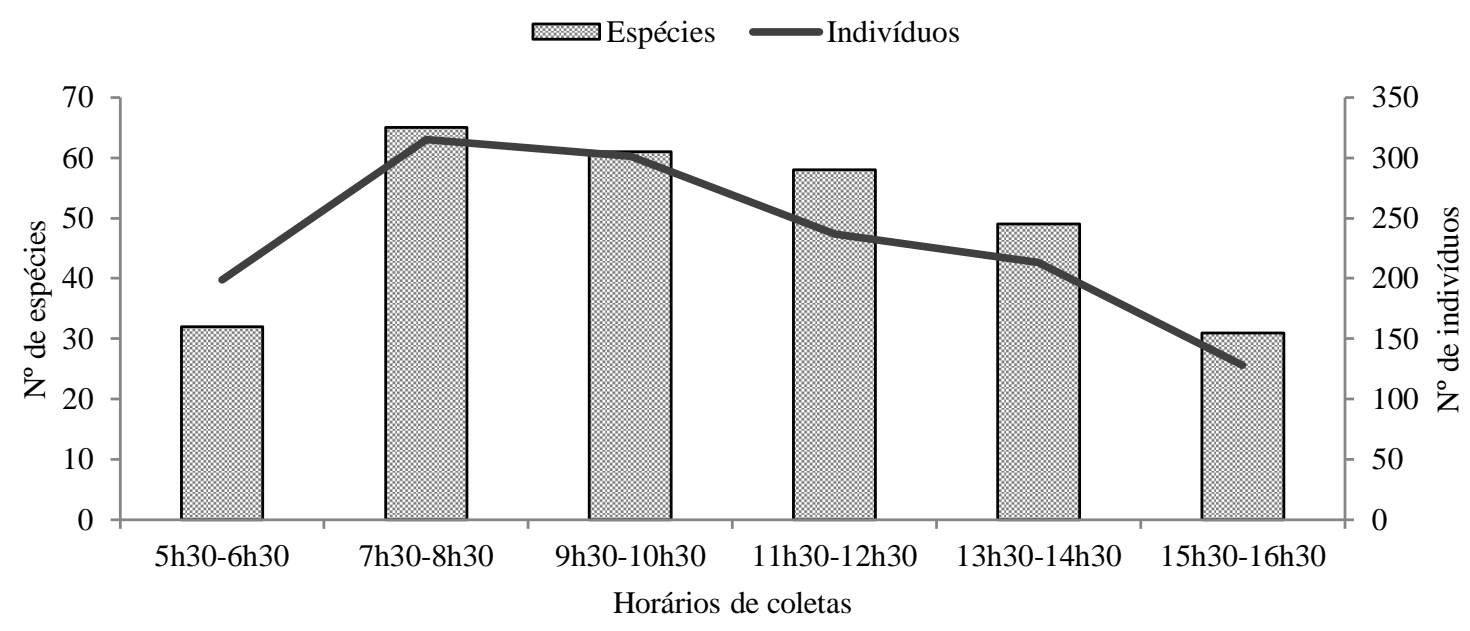

Figura 3 - Distribuição do número de indivíduos e de espécies de visitantes florais por horário de coleta ao longo do dia, amostrados no período de setembro de 2008 e agosto de 2009 em um remanescente de Caatinga, Santa Terezinha, Paraíba.

Em termos da metodologia de amostragem esse resultado é interessante, pois Sakagami et al. (1967), no trabalho pioneiro que propôs os procedimentos padronizados para levantamentos de faunas locais de abelhas, sugeriram que as coletas fossem feitas em quatro horas por dia de coleta, distribuídas entre 9h30 e 14h30, justificando serem os horários de maior atividade das abelhas. Mas, conforme demonstrado neste levantamento em área de caatinga, os horários de maior atividade para visitantes florais, e abelhas em particular, foram entre $7 \mathrm{~h} 30$ e $14 \mathrm{~h} 30$, especialmente os do período da manhã. E em horários anteriores a $7 \mathrm{~h} 30$ foram coletadas espécies não registradas nos restantes. É possível que se a amostragem nos horários seguintes fosse intensificada, por exemplo, pelo aumento no 
número de dias de coleta, essas espécies poderiam ter maior probabilidade de serem coletadas.

Caso a amostragem dos visitantes florais fosse restrita aos horários entre $9 \mathrm{~h} 30$ e $14 \mathrm{~h} 30$ como sugeridos no esquema original por Sakagami et al. (1967), vinte e cinco espécies (10 spp. de moscas; 5 spp. de abelhas; 5 spp. de borboletas; 4 spp. de vespas e uma sp. de besouro) não teriam sido registradas pois foram coletadas exclusivamente entre 5 h30 e 8 h30 e quase $37 \%$ dos indivíduos não teriam sido amostrados. Os referidos dados evidenciam a importância da amostragem no intervalo adotado para estudo nessa região.

Relação entre visitantes florais e plantas visitadas. Sessenta e cinco espécies de plantas foram registradas com flores durante o período de estudo. Porém, os visitantes florais foram coletados em apenas 38 espécies vegetais, distribuídas em 20 famílias botânicas (Tabela 5). As famílias que receberam o maior número de visitas dos antófilos foram Convolvulaceae, Lamiaceae, Fabaceae,
Malvaceae e Euphorbiaceae. Essas famílias botânicas receberam juntas $75 \%$ do total de visitas.

A maior diversidade de espécies de antófilos foi registrada em Jacquemontia sp. (23 spp.). Essa espécie foi visitada por espécies de todas as ordens de insetos visitantes florais amostradas no presente estudo. Outras plantas com maiores riquezas de visitantes foram Stilpnopappus sp. (13 spp.), Croton blanchetianus (12 spp.), Sida galheirensis Ulbr. (11 spp.), Piptadenia stipulacea e Pfaffia sp., ambas com 10 espécies (Tabela 5).

As plantas mais visitadas durante o período de amostragem dos visitantes florais em ordem decrescente foram Jacquemontia sp., Hyptis suaveolens (L.) Poit., Sida galheirensis, Piptadenia stipulacea e Cynophalla flexuosa (Tabela 5). Essas espécies receberam juntas $61,1 \%$ do total de visitas, durante o período de estudo.

O maior número de espécies com flores visitadas ocorreu de março a julho, que corresponde a grande parte do período chuvoso e início do período seco.

Tabela 5. Plantas visitadas com as respectivas famílias botânicas, número total de visitas e número de espécies de visitantes florais, amostrados em área de Caatinga, de setembro de 2008 a agosto de 2009, na Fazenda Tamanduá, em Santa Terezinha, Paraíba.

\begin{tabular}{|c|c|c|c|}
\hline Espécies de plantas & Famílias & $\mathrm{N}^{\circ}$ de visitas & $\mathrm{N}^{\circ}$ de spp. \\
\hline Jacquemontia sp. & Convolvulaceae & 209 & 23 \\
\hline Hyptis suaveolens (L.) Poit. & Lamiaceae & 98 & 6 \\
\hline Sida galheirensis Ulbr. & Malvaceae & 51 & 11 \\
\hline Piptadenia stipulacea (Benth.) Ducke & Fabaceae & 28 & 10 \\
\hline Cуnорhalla flexиosa (L.) J.Presl & Capparaceae & 26 & 6 \\
\hline Bignoniaceae 1 & Bignoniaceae & 25 & 5 \\
\hline Stilpnopappus sp. & Asteraceae & 25 & 13 \\
\hline Cenostigma sp. & Fabaceae & 19 & 9 \\
\hline Manihot catingae Ule & Euphorbiaceae & 19 & 2 \\
\hline Waltheria cf. indica $\mathrm{L}$. & Malvaceae & 16 & 5 \\
\hline Cardiospermum corindum $\mathrm{L}$. & Sapindaceae & 15 & 4 \\
\hline Centratherum punctatum Cass. & Asteraceae & 14 & 8 \\
\hline Croton blanchetianus Pohl & Euphorbiaceae & 12 & 12 \\
\hline Anadenanthera colubrina (Vell.) Brenan & Fabaceae & 11 & 4 \\
\hline Pfaffia sp. & Amaranthaceae & 11 & 10 \\
\hline Combretum leprosum Mart. & Combretaceae & 10 & 8 \\
\hline Senna macranthera (DC. ex Collad.) H.S. Irwin \& Barneby & Fabaceae & 9 & 4 \\
\hline Croton glandulosus L. & Euphorbiaceae & 8 & 2 \\
\hline Bauhinia cheilantha (Bong.) Steud. & Fabaceae & 8 & 2 \\
\hline Polygala sp. & Polygalaceae & 7 & 7 \\
\hline Aspidosperma pyrifolium Mart. & Apocynaceae & 6 & 1 \\
\hline Commiphora leptophloeos (Mart.) J.B. Gillett & Burseraceae & 6 & 1 \\
\hline Acanthaceae 1 & Acanthaceae & 6 & 1 \\
\hline Amburana cearensis (Allemão) A.C. Sm. & Fabaceae & 5 & 4 \\
\hline Rubiaceae 1 & Rubiaceae & 3 & 3 \\
\hline Heliotropium sp. & Boraginaceae & 3 & 1 \\
\hline Diodia $\mathrm{sp}$. & Rubiaceae & 3 & 2 \\
\hline Ipomoea rosea Choisy & Convolvulaceae & 3 & 3 \\
\hline Ipomoea $\mathrm{sp}$. & Convolvulaceae & 3 & 3 \\
\hline Convolvulaceae 1 & Convolvulaceae & 3 & 3 \\
\hline Lantana camara $\mathrm{L}$. & Verbenaceae & 3 & 1 \\
\hline Erythroxylum pungens O.E. Schulz & Erythroxylaceae & 2 & 2 \\
\hline Stachytarpheta sanguinea Mart. ex Schauer & Verbenaceae & 2 & 1 \\
\hline Jatropha mollissima (Pohl) Baill. & Euphorbiaceae & 1 & 1 \\
\hline Allamanda blanchetii A. DC. & Apocynaceae & 1 & 1 \\
\hline Cochlospermum regium (Schrank) Pilg. & Bixaceae & 1 & 1 \\
\hline Macroptilium gracile (Poepp. ex Benth.) Urb. & Fabaceae & 1 & 1 \\
\hline Walteria sp. & Malvaceae & 1 & 1 \\
\hline
\end{tabular}


Em um estudo do sistema de polinização de 147 espécies de plantas da Caatinga, foi verificado que a polinização por insetos é o sistema de polinização mais representativo, com um percentual de $69,9 \%$, sendo a maior parte polinizada por abelhas $(43,1 \%$ do total), e que apenas 5,2\% são polinizadas por borboletas e mariposas (MACHADO; LOPES, 2003). No entanto, na área estudada foi observada uma elevada abundância de lepidópteros, com uma diversidade de espécies significativa, se comparada à registrada para outros grupos como as abelhas. No entanto, a presença de visitantes florais não tem relação direta com as síndromes de polinização, uma vez que muitos visitantes florais não são polinizadores efetivos. Pascarella et al. (2001), ao estudarem insetos visitantes florais, relatam que algumas espécies podem não ser polinizadoras efetivas, apenas se alimentam de estruturas florais ou de sementes em desenvolvimento (dípteros e coleópteros), usam as flores como locais para capturar presas (coleópteros e vespas) ou como locais de repouso (dípteros) ou ainda para realizar postura e/ou copular (CORLETT, 2004).

Além disso, muitas plantas podem ser polinizadas por uma diversidade de grupos, não apresentando especificidade. De acordo com Machado e Lopes (2003), as borboletas apresentam comportamento generalista, visitando várias espécies de plantas, apesar das mesmas autoras terem observado a existência de especificidade.

\section{CONCLUSÕES}

Verificou-se uma guilda de visitantes florais diversa na área de estudos. Hymenoptera apresentou a maior riqueza de visitantes florais e Lepidoptera a maior abundância de indivíduos.

As espécies predominantes de visitantes foram Apis mellifera (Hymenoptera) e Eurema elathea (Lepidoptera), que se destacaram pela alta dominância e constância.

Foi observado um padrão sazonal na riqueza de espécies e abundância para as principais ordens de visitantes florais amostradas (Hymenoptera, Lepidoptera e Diptera), com uma menor abundância e riqueza durante o período seco. Em geral, himenópteros, lepidópteros e dípteros, apresentaram padrões fenológicos semelhantes, caracterizando-se por um aumento de atividade no período chuvoso e com algumas espécies ativas durante todo o ano, incluindo espécies solitárias.

Os visitantes florais apresentaram maior número de indivíduos em atividade durante o período da manhã (entre $5 \mathrm{~h} 30$ e 10h30). No intervalo entre $7 \mathrm{~h} 30$ e $8 \mathrm{~h} 30$ houve a maior riqueza e abundância de visitantes florais amostrados, com o registro de espécies coletadas exclusivamente nos dois primeiros horários estudados, o que indica a sua inclusão em futuros levantamentos na Caatinga.

\section{AGRADECIMENTOS}

Agradecemos ao Sr. Pierre Landolt proprietário da Fazenda Tamanduá por disponibilizar a área para realização da pesquisa.

\section{REFERÊNCIAS}

AGUiAR, C. M. L.; MARTinS, C. F.; MOURA, A. C. A. Recursos florais utilizados por abelhas (Hymenoptera, Apoidea) em área de Caatinga (São João do Cariri, Paraíba). Revista Brasileira de Biologia, v.10, n.2, p.101-117, 1995.

AGUIAR, C. M. L.; MARTINS, C. F. Abundância relativa, diversidade e fenologia de abelhas (Hymenoptera, Apoidea) na Caatinga, São João do Cariri, Paraíba, Brasil. Iheringia, sér. Zool., v.83, p.151-163, 1997.

AGUiAR, C. M. L.; ZANELLA, F. C. V. Estrutura da Comunidade de Abelhas (Hymenoptera: Apoidea: Apiformis) de uma Área na Margem do Domínio da Caatinga (Itatim, BA). Neotropical Entomology, v.34, n.1, p.15-24, 2005.

ÁlVARES, C. A.; STAPE, J. L.; SENTELHAS, P. C.; GONÇALVES, J. L. M.; SPAROVEK, G. Köppen's climate classification map for Brazil. Meteorologische Zeitschrift, v. 22, n. 6, p. 711-728. 2013.

ANDENA, S. R.; BEGO, L. R.; MECHI, M. R. A comunidade de abelhas (Hymenoptera, Apoidea) de uma área de cerrado (Corumbataí, SP) e suas visitas às flores. Revista Brasileira de Zoociências, v.7, n.1, p.55-91, 2005.

ANSELMO, F. A.; KERPEL, S. M.; FERREIRA JÚNIOR, A.; ZANELLA, F. C. V. Abundância, riqueza de espécies e sazonalidade de borboletas (Lepidoptera: Hesperioidea e Papilionoidea) visitantes florais em área de Caatinga e floresta ciliar no Semiárido paraibano. Biologia \& Farmácia e Manejo Agrícola, Campina Grande, v. 10, n. 1, p. 97-110, 2014.

APG IV. An update of the Angiosperm Phylogeny Group classification for the orders and families of flowering plants: APG IV. Botanical Journal of the Linnean Society, v.181, p.1-20, 2016.

AOKI, C.; SIGRIST, M. R. Inventário dos visitantes florais no Complexo Aporé-Sucuriú. In: PAGOTTO, T. C. S.; SOUZA, P. R. (orgs.). Biodiversidade do Complexo Aporé-Sucuriú: Subsídios à conservação e manejo do bioma Cerrado. Ed. UFMS. Campo Grande, MS. 2006. p.143-162.

BATALHA FILHO, H.; NUNES, L. A.; PEREIRA, D. G.; WALDSCHMIDT, A. M. Inventário da fauna de abelhas (Hymenoptera, Apoidea) em uma área de 
Caatinga da região de Jequié, BA. Bioscience Journal, v. 23, Supplement 1, p. 24-29, 2007.

CAMARGO, E., ROdRIGUES, L. C., ARAujO, A. C. Pollination biology and reproduction of Seemannia sylvatica (Kunth) Hanstein (Gesneriaceae) in the Serra da Bodoquena National Park, Mato Grosso do Sul. Biota Neotropica. v.11, n.4, p.125-130. 2011.

COLWELL, R.K. 2005. EstimateS - statistical estimation of species richness and shared species from samples. User's guide. Disponível em: <http://viceroy.eeb.uconn.edu/EstimateS >. Acesso em: 01 fev. 2016.

CORLETT, R. T. Flower visitors and pollination in the Oriental (Indomalayan) Region. Biological Reviews, v.79, p.497-532, 2004.

FAHRIG, L. Effects of habitat fragmentation on biodiversity. Annual Review of Ecology, Evolution, and Systematics, v.34, p.487-515, 2003.

FREITAS, B. M.; SOUSA, R. M.; BOMFIM, I. G. A. Absconding and migratory behaviors of feral Africanized honey bee (Apis mellifera L.) colonies in NE Brazil. Acta Scientiarum. Biological Sciences, v.29, n.4, p.381-385, 2007.

HAMMER, O.; HARPER, D. A. T.; RYAN, P. D. PAST: Paleontological Statistics Software Package for Education and Data Analysis. Palaeontologia Electronica, v.4, n.1, 2001. 9 p.

IMPERATRIZ-FONSECA, V. L., CANHOS, D. A. L., ALVES, D. A. \& SARAIVA, A. M. 2012. Polinizadores e polinização - um tema global. p. 25-45 In: IMPERATRIZ-FONSECA, V. L., CANHOS, D. A. L., ALVES, D. A. \& SARAIVA, A. M. Polinizadores no Brasil. Edusp, São Paulo. 2012. 485 p.

LOPES, L. A.; BLOCHTEIN, B.; OTT, A. P. Diversidade de insetos antófilos em áreas com reflorestamento de eucalipto, município de Triunfo, Rio Grande do Sul, Brasil. Iheringia, Série Zoológica, v. 97, n.2, p.181-193, 2007.

MACHADO, I. C.; LOPES, A. V. Recursos florais e sistemas de polinização e sexuais em caatinga. In: LEAL, I. R.; TABARELli, M.; SILVA, J. M. C. (orgs.) Ecologia e conservação da caatinga. Editora Universitária, Universidade Federal de Pernambuco, Recife, 2003. p.515-563.

MAGURRAN, A. E. Medindo a Diversidade Biológica. Editorial. UFPR, 2011. 261 p.

MILET-PINHEIRO, P.; SCHLINDWEIN, C. Comunidade de abelhas (Hymenoptera, Apoidea) e plantas em uma área do Agreste pernambucano, Brasil. Revista Brasileira de Entomologia, v.52, n.4, p.625636, 2008.
MORETI, A. C. C. C.; ANICETO, D. A.; D’ÁVILA, M.; VIEIRA, G. H. C.; MARCHINI, L. C. Abelhas visitantes em vegetação de diferentes áreas remanescentes de cerrado. Magistra, v.18, n.4, p.229-248, 2006.

MOURA, D. C., PEREIRA, T. M. S., FARIAS, G. C. F., LEITE, J. E. M. Abelhas e espécies melitófilas da mata ciliar do riacho Salgadeira, município de Alcantil, Paraíba. Revista Verde de Agroecologia e Desenvolvimento Sustentável, v.13, n.3, p.392-398, 2018.

OLLERTON, J.; WINFREE, R. TARRANT, S. How many flowering plants are pollinated by animals? Oikos.120, p.321-326, 2011.

PASCARELLA, J. B.; WADDINGTON, K. D.; NEAL, P. R. Non-apoid flower-visiting fauna of Everglades National Park, Florida. Biodiversity and Conservation, v.10, p.551-566, 2001.

PIGOZZO, C. M.; VIANA, B. F. Estrutura da rede de interações entre flores e abelhas em ambiente de caatinga. Oecologia Australis, v.14, n.1, p.100-114, 2010.

PINHEIRO, M.; ABRAÃO, B. E.; HARTERMARQUES, B.; MIOTTO, S. T. S. Floral resources used by insects in a grassland community in Southern Brazil. Revista Brasileira de Botânica, v.31, n.3, p.469-489, 2008.

PROCTOR, M.; YEO, P.; LACK, A. The Natural History of pollination. Portland: Timber Press, 1996. 479 p.

SAKAGAMI, S. F.; LAROCA, S.; MOURE, J. S. Wild bee biocoenotics in São José dos Pinhais (PR), South Brazil. Preliminary report, Journal of the Faculty of Science Hokkaido University, Series IV, Zool, v.16, p.253-291, 1967.

SCHWARTZ-FILHO, D. L.; LAROCA, S. A comunidade de abelhas silvestres (Hymenoptera, Apoidea) da Ilha das Cobras (Paraná, Brasil): aspectos ecológicos e biogeográficos. Acta Biológica Paranaense, v.28, p.18-101, 1999.

SANTOS et al. Abelhas (Hymenoptera: Anthophila) em uma área de caatinga no estado de Pernambuco. Biodiversidade, v.19, n.3, p.92-103, 2020.

SILVA, C. M.; SILVA, C. I.; HRNCIR, M.; QUEIROZ, R. T.; IMPERATRIZ-FONSECA, V. L. Guia das Plantas - Visitadas por abelhas da Caatinga. Fortaleza - CE. Fundação Brasil Cidadão, 2012. 195p.

SILVA, J. M. C., BARBOSA, L. C. F., LEAL, I. R.; TABARELLI, M. The Caatinga: Understanding the Challenges. In: SILVA J. M. C., LEAL I. R.; TABARELlI, M. (eds.). Caatinga The Largest Tropical Dry Forest Region in South America. Springer International Publishing. 2017. p.3-19. 
SILVEIRA NETO, S.; NAKANO, O.; BARBIN, D.; VILLA NOVA, N. A. Manual de ecologia de insetos. São Paulo: Ceres. 1976. 419 p.

VIANA, B. F. A comunidade de abelhas (Hymenoptera, Apoidea) das dunas interiores do rio São Francisco, Bahia, Brasil. Anais da Sociedade Entomológica do Brasil, v.28, n.4, p.635-645, 1999.
ZANELLA, F. C. V. Abelhas da Estação Ecológica do Seridó (Serra Negra do Norte, RN): Aportes ao conhecimento da diversidade, abundância e distribuição espacial das espécies na caatinga. In: MELO, G. A. R.; ALVES DOS SANTOS, I. G. A. R. (ed.). Apoidea Neotropica. Homenagem aos 90 anos de Jesus Santiago Moure. UNESC, Criciúma, 2003. p. 231-240.

ZANELlA, F. C. V.; MARTINS, C. F. Abelhas da caatinga: Biogeografia, ecologia e conservação. In: LEAL, I. R.; TABARELLI, M.; SILVA. J. M. C. (eds.), Ecologia e conservação da caatinga. Edit. Universitária, UFPE, Recife, 2003. p. 75-134. 